\title{
POLICY ADVOCACY: CONTRIBUIÇÕES PARA A CONSTRUÇÃO DE UM CONCEITO A PARTIR DE UMA REVISÃO SISTEMÁTICA DA LITERATURA
}

\section{POLICY ADVOCACY: CONTRIBUTIONS FOR THE DEFINITION OF A CONCEPT ORIGINATED FROM A SYSTEMATIC REVIEW OF THE LITERATURE}

\section{Viviane Regina da Silva ${ }^{1}$}

Resumo: A prática de policy advocacy implica em dar voz política a uma mensagem ligada à defesa de uma causa, como instrumento de influência da opinião pública e dos tomadores de decisão. O presente artigo visa contribuir para fomentar os estudos sobre a ascensão do fenômeno de $p o$ licy advocacy na contemporaneidade e suscitar o debate desta temática no âmbito acadêmico nos campos de estudos de Direitos Humanos e Políticas Públicas. Complementarmente poderá corroborar com a discussão da temática entre os tradicionais atores de direitos humanos e políticas públicas no Brasil, pois sabe-se que o desenvolvimento de estudos planejamento de estratégias de policy advocacy é de interesse das organizações nacionais e internacionais do terceiro setor, de grupos de pressão, think tanks, mo- vimentos sociais, mídias tradicionais e sociais e do próprio governo. Face ao exposto, o presente artigo objetivou levantar as divergências conceituais acerca da definição de policy advocacy por intermédio da metodologia de revisão sistemática da literatura e análise de conteúdo, demonstrando a evolução conceitual e seus distintos pontos de vista, de modo a contribuir para a construção de um conceito adequado para a literatura nacional, contemplando a característica interdisciplinar dos campos de estudos de Direitos Humanos e Políticas Públicas. A partir de uma revisão sistemática da literatura constatou-se que no Brasil, ainda são recentes as pesquisas sobre policy advocacy e, a princípio, a maioria dos estudos concernentes a esta temática apresentam ênfase nos modelos de análise e na caracterização

1 Graduada em Administração pela Universidade Federal de Santa Catarina (UFSC). Graduanda em Direito pela UFSC. Mestranda em Administração pela Universidade do Estado de Santa Catarina UDESC. Administradora na UFSC. Pesquisadora do Grupo de Pesquisa Constitucionalismo Político da UFSC e do Zeitgeist Grupo de Pesquisa em Teoria do Direito da Universidade do Sul de Santa Catarina (Unisul). E-mail: viviane.regina@ufsc.br. 
dos processos de negociação das políticas setoriais específicas, estando o termo policy advocacy fortemente associado às terminologias de Advocacy Coalition Framework (ACF), Advocacy e Media Advocacy.

Palavras-chave: Policy advocacy. Políticas públicas. Direitos humanos.

Abstract: The practice of policy advocacy implies in giving political voice to a message linked to the defense of a cause, as an instrument of influence of public opinion and of the decision makers. The article aims to contribute to lift up studies about the phenomenon of policy advocacy nowadays and steer a discussion of this subject in the scope of academic production in the area of Human Rights and Public Policies. It can also corroborate with the thematic discussion among the traditional actors of human rights and public policies in Brazil, because people have known that the development of studies of strategy planning of policy advocacy is of interest to national and international organizations of the third sector, of groups of influence, think tanks, social movements, conservative and secular media, and of the government itself. In light of the aforesaid, the article has aimed to raise the conceptual conflicts about the definition of policy advocacy by way of the method of systematic review of the literature and content analyses, showing conceptual evolution and its distinct points of view, in a way of contributing to the construction of an adequate concept for the national literature, contemplating the interdisciplinary characteristic of the areas of Human Rights and Public Policies. Starting from a systematic review of the literature, there was a finding that in Brazil, the research about policy advocacy is quite recent, and at first, the majority of the studies about this subject have presented an emphasis in the methods of analyses and in the characterization of the negotiating procedures of the sectoral policies, the term policy advocacy being strongly associated with the terms of Advocacy Coalition Framework (ACF), Advocacy and Media Advocacy.

Keywords: Policy advocacy. Public policy. Human rights.

\section{INTRODUÇÃO}

Presencia-se contemporaneamente uma ênfase na relação dialética entre as temáticas de Políticas Públicas e Direitos Humanos. Sob os auspícios da Constituição Federal de 1988 e os direitos e garantias fundamentais nela salvaguardados, sabe-se que a efetivação dos direitos humanos demanda políticas públicas que, por sua vez, devem ser implementadas pela via do direito (MAGALHÃES; SANTOS LIMA, 2012; p. 03). Nesse cenário, percebe-se a necessidade de correlacionar os estudos da teoria jurídica com a Ciência Política, Sociologia e Admi- 
nistração Pública.

À luz de Fábio Konder Comparatto (2006, p. 12), os direitos humanos tratam de algo que é inerente à própria condição humana, de modo que "todos os seres humanos têm direito a serem respeitados, pelo simples fato de sua humanidade". Em âmbito nacional, o inciso II do art. $4^{\circ}$ da Constituição Federal de 1988 prevê que a República Federativa do Brasil rege suas relações internacionais pelo princípio da prevalência dos direitos humanos. Complementarmente, o parágrafo $3^{\circ}$ do art. $5^{\circ}$ da Carta Magna, prevê que "[...] os tratados e convenções internacionais sobre direitos humanos que forem aprovados, em cada Casa do Congresso Nacional, em dois turnos, por três quintos dos votos dos respectivos membros, serão equivalentes às emendas constitucionais [...]" (BRASIL, 1988).

Depreende-se do exposto que a Constituição Federal de 1988 assegura uma promessa de garantia de efetivação de direitos individuais e sociais atrelados aos direitos humanos. Dessa feita, importa elucidar que, tradicionalmente, a efetividade dos direitos humanos condiciona-se à realização das promessas neles contidas. Todavia, a ilustre jurista Julianana Magalhães afirma, sob a ótica do paradoxo sistêmico luhmanniano, que "[...] os direitos humanos, enquanto reação à modernidade, encontram resistência à sua efetivação exatamente nas condições da modernidade". (MAGALHÃES; SANTOS LIMA, 2012).

$\mathrm{Na}$ perspectiva sistêmica de políticas públicas de Easton (1965), as demandas se dão na medida em que os indivíduos e grupos se articulam na tentativa de influenciar a política pública com o objetivo de dar respostas às condições ambientais reais ou percebidas. No entanto, comumente o número potencial de questões públicas supera - e muito - as capacidades de processamento dos membros do parlamento e dos gestores públicos.

Sabe-se que o enfrentamento de um problema público se dá por intermédio de diretrizes elaboradas a partir de políticas 
públicas, as quais são motivadas pelo entendimento de que um problema tem relevância para a coletividade (SECCHI, 2013). Daí a importância do processo de formação de agenda, o qual é concebido como um conjunto de problemas ou temas entendidos como relevantes e que se tornam alvo de atenção e de ação por parte do Estado (CALMON, COSTA, 2007; SECCHI, 2013).

Nessa seara, Libardoni apresenta a temática de advoca$c y$, pertencente ao campo das políticas públicas, como um instrumento para articulação para defesa de uma causa sob a perspectiva dos objetivos e interesses coletivos, conforme exposto a seguir

[...] advocacy tem um significado mais amplo, denotando iniciativas de incidência ou pressão política, de promoção e defesa de uma causa e/ou interesse, e de articulações mobilizadas por organizações da sociedade civil com o objetivo de dar maior visibilidade a determinadas temáticas ou questões no debate público e influenciar políticas visando à transformação da sociedade. (LIBARDONI, 2000, p. 02)

Cabe evidenciar que a partir de uma revisão literária, sabe-se que tanto advocacy quanto a policy advocacy compreendem a defesa de políticas públicas, as quais podem ser realizadas perante os poderes Executivo, Legislativo e Judiciário, além do Ministério Público, da mídia (tradicional e mídias sociais), dos formadores de opinião e a sociedade em geral (BRELÀZ, 2007; LIBARDONI, 2000). Assim, as atividades de policy advocacy (ou advocacy) compreendem um processo de conscientização e mobilização de formadores de opinião e da própria população visando à mudança de paradigmas por intermédio de proposições de demandas e incentivo à atuação do poder público.

Contudo, existe uma lacuna relativa ao estudo de policy advocacy no cenário nacional. Trata-se de um tema ainda muito incipiente dado que são escassas as pesquisas científicas e publicações acerca desta temática no Brasil. A falta de reconhecimento do termo e de tradução da expressão para o idioma 
português impõe esta questão.

Embora a temática de policy advocacy esteja apenas começando a ser estudada no Brasil, e seus construtos mais relevantes tenham sido identificados recentemente nas pesquisas nacionais, na literatura internacional, esse é um tema em consolidação, pois está intrinsecamente ligado à expansão das estratégias de comunicação e articulação dos movimentos sociais em consonância com a ampliação da participação da sociedade nas decisões públicas (BRELÀZ, 2009; ROLAND, 2000; DALLARI et al., 1996).

Ante ao exposto, o objetivo deste artigo é levantar as divergências conceituais acerca da definição de policy advocacy por intermédio da metodologia de revisão sistemática da literatura e análise de conteúdo, demonstrando a evolução conceitual e seus distintos pontos de vista, de modo a contribuir para a construção de um conceito adequado para a literatura nacional de políticas públicas.

\section{PROCEDIMENTOS METODOLÓGICOS}

O presente estudo é classificado como qualitativo, exploratório e teórico (CRESWELL, 2010; DEMO, 2000) pois se dedica à reconstrução de conceitos por intermédio do aprimoramento de fundamentos teóricos com base em análises conceituais comparativas. Para tanto, este artigo utiliza-se das metodologias de revisão sistemática da literatura (FERENHOF; FERNANDES, 2015) e análise de conteúdo (BARDIN, 1979; MORAES, 1999; NAVARRO; DIAS, 1994). Compreende uma pesquisa pautada em livros e trabalhos científicos que abordassem o conceito de policy advocacy.

A busca pelos artigos foi realizada por intermédio das bases de dados Scientific Periodicals Electronic (Spell) e Scientific Electronic Library Online (SciELO). Os termos utilizados nas buscas das bases de dados foi Policy Advocacy, juntamen- 
te com o operador booleano AND, a fim de buscar também os estudo que contemplavam o termo advocacy. Manteve-se sempre a mesma query para garantir a consistência. Em todas as bases de dados, optou-se por selecionar somente os artigos revisados por pares entre os anos de 2012 a 2015. Assim, inicialmente foram encontrados 4 (quatro) artigos no Spell e 14 (quatorze) artigos no SciELO.

Com a execução do procedimento de exclusão das duplicidades restaram 16 (dezesseis) artigos. Para operacionalização deste estudo foram analisados 4 (quatro) trabalhos científicos nacionais e 12 (doze) pesquisas internacionais. Os artigos selecionados foram submetidos à análise de conteúdo por intermédio da técnica de "leitura flutuante" (BARDIN, 1979) dos resumos, com o objetivo de identificar se contemplavam o conceito de policy advocacy (ou advocacy como seu sinônimo) e/ou conceber tais conceitos em estudos empíricos.

Deste total, 5 (cinco) apresentam o conceito de advocacy, seja como sinônimo de policy advocacy, seja correlacionado com outros termos acoplados à terminologia de advocacy. Após essa etapa, os artigos pré-selecionados foram submetidos ao critério de "relevância conceitual" proposto por Nicolai e Seidl (2010). Por fim, os estudos resultantes deste processo compõem o presente artigo e constam nas referências.

No que tange a policy advocacy no Brasil, a busca se concentrou na base de dados Spell. A busca foi iniciada nesta base de dados abrangendo o conceito de policy advocacy e sua respectiva tradução para o português (advocacia política). Foram identificados 4 (quatro) artigos, que foram todos selecionados após a leitura dos resumos.

Quando da análise do referencial teórico, foram encontrados termos presentes nos conceitos de advocacy, compreendendo: policy advocacy, media advocacy e advocacy coalition framework. Cada conceito foi classificado em conformidade com os 
termos detentores a fim de verificar a abrangência dos termos.

A pesquisa não resultou em no encontro de estudos dispostos a criar ferramentas visando à viabilização de pesquisas empíricas.

\section{POLICY ADVOCACY: DEFINIÇÕES CONCEITUAIS E ORIGENS HISTÓRICAS}

A raiz etimológica da palavra "política" (em inglês, policy) é proveniente do termo grego politika, o qual tem sua gênese na palavra polis, que significa "cidade" ou "cidade-estado". Segundo a visão aristotélica, a polis é uma comunidade política subordinada a um pacto comportamental e moral (em grego, politei) tendo em vista o bem viver para os seus cidadãos (HASHIZUME, 2014).

Etimologicamente, o termo advocacy tem origem histórica no Direito Romano e é derivada do latim advocatus, que é o particípio de advocare, composto de ad e vocare. O prefixo latino $a d$ significa "aproximação, movimento para junto" enquanto que a palavra vocare é proveniente dos radicais latinos vox e vocis, que significa "voz". Viaro (1999) afirma que advoco é "chamar para perto", daí advocatus, "o que foi chamado para perto" (a fim de ajudar), isto é o advogado.

Os relatos históricos sobre a prática de policy advocacy são milenares. Um dos primeiros relatos da cultura judaico-cristã se deu no continente africano às margens do Rio Nilo e está registrado no Pentateuco (do grego, "Cinco Rolos") também denominado de Torá (do hebraico, ensinamento, instrução, lei), que constitui no texto central do judaísmo (CRÜSEMANN, 2001) e compõe os cinco primeiros livros da Bíblia, obra literária que fundamenta as bases do cristianismo. De acordo com Arrais (2011), o faraó Apopi I era o governante de origem hicsa do Egito da dinastia XV e o livro de Gênesis descreve que o líder egípcio fora aconselhado por um escravo presidiário a dar início 
a uma política de abastecimento alimentar de curto e médio prazo como estratégia de combate à fome, enfrentamento às secas e uma futura crise econômica. Tal conselho foi dado por José, que era de origem hebraica. Politicamente, na História Antiga, os hebreus caracterizavam-se como uma população pobre e explorada pelos reis e governantes das cidades-reino da Mesopotâmia, de Canaã e do Egito. José idealizou uma estratégia de armazenamento e distribuição de grãos evitando que a epidemia de fome consumisse o reino do Faraó Apopi I e também os reinos vizinhos, conforme a descrição do relato bíblico:

Agora dou a seguinte sugestão ao faraó: o faraó deve escolher um homem criterioso e sábio para comandar a terra do Egito. O faraó também deve nomear administradores sobre a terra, para recolher a quinta parte de toda a colheita da terra do Egito durante os sete anos de fartura. Esses administradores deverão recolher toda a colheita de trigo dos anos bons que virão, o qual será estocado em armazéns, sob o controle do faraó, para mantimento nas cidades. Esse mantimento servirá como reserva para os sete anos de fome que haverá no Egito, para que a nação sobreviva à crise. (NOVA BÍBLIA VIVA; GÊNESIS, 41:33-36).

Nesse episódio do Egito Antigo, configurou-se a prática de policy advocacy aplicada a uma política de segurança alimentar e nutricional bem como uma política de soberania alimentar. Contemporaneamente a advocacy institucionalizada desta causa é realizada precipuamente pela Organização das Nações Unidas para Alimentação e Agricultura (FAO).

A partir da leitura da obra "Política", do filósofo grego antigo Aristóteles, sabe-se que a filosofia aristotélica surgiu há aproximadamente 2.500 anos e deu origem à expressão grega zoon politikon, da qual se depreende que o homem é um animal político. $\mathrm{Na}$ Grécia Antiga as polis eram comunidades organizadas compostas por polites (cidadãos) que eram homens nascidos no solo da cidade, livres e iguais, dotados de isonomia (igualdade perante a lei). Todos os cidadãos gregos deste 
período também eram dotados de isegoria, ou seja, o direito de se pronunciar publicamente na eclésia sobre ações que a cidade deve ou não deve realizar. A prática milenar da isegoria está alinhada ao conceito contemporâneo de policy advocacy na medida em o desenvolvimento das habilidades de oratória e argumentação passou a ser uma necessidade política, pois falar com clareza e argumentar de modo persuasivo era um imperativo na da defesa de causas e interesses coletivos nas assembleias e nos tribunais gregos.

Por influência da longa tradição do associativismo nos Estados Unidos (TOCQUEVILLE, 1998) e do caráter liberal da sociedade estadunidense, contemporaneamente o fenômeno de policy advocacy faz parte das organizações da sociedade civil (OSCs) norte-americanas, face ao precoce amadurecimento e estruturação do terceiro setor neste país em consonância com os movimentos sociais que efetivaram a luta por diversos direitos e interesses nos EUA (BRELÀZ, 2007). No Brasil, a partir dos anos 70, as organizações da sociedade civil se utilizaram de ferramentas de policy advocacy para estruturar e ampliar fortemente sua participação no contexto brasileiro, estimuladas pela luta por democratização dos movimentos sociais (BRELÀZ, 2007).

$\mathrm{O}$ início dos estudos sobre a temática de policy advocacy se deu na segunda metade do século XX nos Estados Unidos e até os dias atuais esta é uma temática estudada majoritariamente pela comunidade acadêmica norte-americana (BRELÀZ, 2007). Segundo Fox (2001), a partir da ascensão dos movimentos de direitos civis nos Estados Unidos durante a década de 1960, o termo advocacy passou a ser utilizado não somente para a defesa jurídica de indivíduos, mas fora ampliado para três direções justiça:

[...] defesa dos interesses dos grupos inteiros de pessoas excluídas ou marginalizadas; [...] articulação proativa de 
estratégias de mudança de interesse público, e [...] soma de esforços para a defesa contra uma ampla variedade de abusos do poder público ou exclusão social para além dos problemas estritamente legais [...] (FOX, 2001; p. 616-617).

O termo policy advocacy é pouco conhecido no Brasil e ainda não há uma terminologia equivalente ou tradução exata para a língua portuguesa que contemple satisfatoriamente a amplitude de significado do termo. No idioma espanhol, a expressão policy advocacy é entendida como incidencia política, que significa "pressão política" e no Brasil o termo "advocacia política" é empregado na tradução, ainda não definitiva de policy advocacy. Contudo, na língua portuguesa os termos "advocacia" e "advogar" se referem fundamentalmente a atividades de natureza legal ou jurídica e possuem um entendimento consolidado nas doutrinas, jurisprudências e leis no âmbito nacional. Logo, a utilização da expressão "advocacia política" como tentativa de traduzir literalmente o termo policy advocacy implicaria necessariamente em um desvio de entendimento de um termo de abrangência interdisciplinar. Nesse sentido, Brelàz defende que o termo Advocacy irrompe as fronteiras conceituais jurídicas do campo de estudo do Direito, considerando que

Por advocacy entendemos o ato de identificar, adotar e promover uma causa. É um esforço para moldar a percepção pública ou conseguir alguma mudança seja através de mudanças na lei, mas não necessariamente. (BRELÀZ, 2007; p. 01).

Importa também evidenciar que contemporaneamente em nível nacional o termo advocacy é equivocadamente equiparado ao lobbying. Proveniente do idioma inglês, a expressão lobby significa "antessala" ou "antecâmara" e historicamente refere-se às repartições públicas onde se reuniam os grupos de pressão para organizar as suas demandas (NOGUEIRA apud PORTO, 2011). Conceitualmente, Oliveira (2004, p. 01) define o termo lobbying como sendo "[...] o processo pelo qual os grupos de pressão buscam participar do processo estatal de 
tomada de decisões, contribuindo para a elaboração das políticas públicas de cada país". Complementarmente, para Bobbio, Matteucci e Pasquino, lobbying é definido como

[...] o processo por meio do qual os representantes de grupos de interesses, agindo como intermediários, levam ao conhecimento dos legisladores ou dos decision-makers os desejos dos seus grupos. Lobbying é portanto e sobretudo uma transmissão de mensagens do Grupo de pressão aos decision-makers, por meio de representantes especializados (em alguns casos, como nos Estados Unidos, legalmente autorizados), que podem ou não fazer uso da ameaça de sanções. (BOBBIO; MATTEUCCI; PASQUINO, 1998; p. 563-564).

Ante o exposto, observa-se que as atividades de lobbying estão focadas na comunicação persuasiva junto aos tomadores de decisão de órgãos governamentais ligados ao poder Executivo e Legislativo. Contudo, as práticas de advocacy possuem um escopo mais amplo, com um círculo de interesse e influência maior, conforme aponta o arcabouço conceitual apresentado anteriormente. Logo, conclui-se que o lobbying constitui-se em uma das ferramentas de policy advocacy (BRUM, 2009; BRELÀZ, 2007).

A atividade de lobbying é estigmatizada e dotada de uma carga pejorativa considerando que sua prática não é legalmente regulamentada no Brasil e que o imaginário popular se associa o lobby à corrupção política, tráfico de influência e o exercício antiético de grupos financeiramente poderosos sobre os três poderes. Isso influencia o fato de que as temáticas envolvendo lobby e policy advocacy ainda são pouco estudadas nas universidades brasileiras.

Os primeiros textos brasileiros que discorrem sobre o termo Advocacy em publicações científicas nacionais foram produzidos no final na década de 90 . Uma das obras embrionárias de maior destaque intitula-se "Advocacia em Saúde no Brasil Contemporâneo" (DALLARI, et al, 1996), com a parceria de 
pesquisadores brasileiros do Departamento de Saúde Pública da Universidade de São Paulo e da Faculdade de Medicina da Columbia University dos Estados Unidos e publicado na Revista de Saúde Pública em 1996. Destaca-se também a obra acadêmica intitulada "Advocacy: uma ação política de novo tipo" sob a autoria de Almira Rodrigues (1999), doutora em sociologia pela Universidade de Brasília (UNB), publicado por ocasião do "I Seminário Nacional Mulher Negra, Mídia e Advocacy", promovido pelo Geledés Instituto da Mulher Negra, realizado em abril de 1999 na cidade de São Paulo. É também deste período a obra "Feminismo: ações políticas e instâncias de poder", da psicóloga, pesquisadora de gênero e ativista étnica internacional Edna Maria Santos Roland que aplica o conceito de advocacy na esfera dos estudos de gênero. No texto, Roland (2000, p. 01) afirma que seu objetivo é “[...] introduzir no âmbito do movimento latino-americano e brasileiro o conceito de advocacy".

\section{A AUTOPOIESE DO DIREITO E A PRÁTICA DE POLICY ADVOCACY COMO AGENTE DE IRRITAÇÃO DOS SISTEMAS JURÍDICOS}

Para Magalhães e Santos Lima (2012), a temática dos Direitos Humanos está intrinsecamente atrelada a questão da inclusão social. Nesta seara, cumpre elucidar que os mecanismos de inclusão e exclusão social possuem regramentos próprios para tornar as pessoas partícipes da comunicação social. Ante o exposto, o pensamento de Santos Lima é central e de vital importância para o desenvolvimento do presente estudo:

o "clamar pelos direitos" talvez seja a forma mais efetiva de sensibilização da política e de outros sistemas sociais, que poderiam, neste passo, deixar-se sensibilizar por estes clamores. Os direitos humanos, em que pese a inevitabilidade de sua não-efetividade, fazem-se recorrentemente efetivos nas decisões tanto do sistema jurídico quanto de 
outros sistemas, que por eles se deixam "irritar". (SANTOS LIMA apud MAGALHÃES; SANTOS LIMA, 2012; p. 08, grifo nosso).

O termo "irritar", contido no trecho supracitado, é utilizado pelo sociólogo alemão Niklas Luhmann (1927-1998) acerca do desenvolvimento da Teoria dos Sistemas e da autopoiese aplicada à sociologia do direito. Deste modo, Luhmann (2007) contribuiu para a construção da dinamicidade de um sistema jurídico capaz de adequar-se à hipercomplexidade da sociedade atual. Segundo Guerra Filho (2009, p. 212) na concepção luhmanniana, o sistema jurídico "integra o sistema imunológico" das sociedades, imunizando-as de conflitos entre seus membros, surgidos já em outros sistemas sociais (político, econômico, familiar etc)".

A autopoiese, no âmbito da sociologia do direito, fundamenta-se na ideia de que "[...] a reprodução dos elementos e estruturas do sistema é realizada com a ajuda de seus próprios elementos[...]" (ALFERES, 2010). A teoria luhmanniana ensina que o ambiente pode irritar ou perturbar o sistema, de modo que o sistema venha a autoproduzir-se. Assim, a autopoiese do sistema é fruto do estímulo da irritação provocado pelo ambiente. Nessa seara, Luhmann (1997, p. 68) afirma que "[...] irritações se dão sempre e inicialmente a partir de diferenciações e comparações com estruturas (expectativas) internas aos sistemas, sendo, portanto,-do mesmo modo que informação - necessariamente produto do sistema [...]”. Depreende-se do exposto que é por intermédio da irritação (ou perturbação) que se desenvolve o processamento de informação que somente pode se realizar dentro do sistema. Para melhor compreensão da dinâmica autopoietica concebida por Luhmann (2009), apresenta-se a figura a seguir, que explana o desenho esquemático da abertura do sistema social e do sistema jurídico, sendo as setas elementos representativos das irritações externas (ambiente e demais subsistemas). 


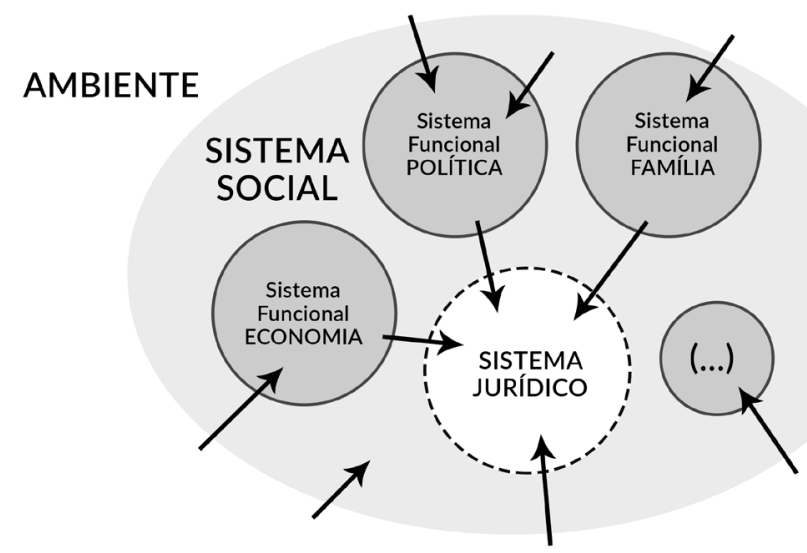

desenho esquemático da abertura do sistema social, e do sistema jurídico, as irritações externas (ambiente e demas subsistemas)

Fonte: ALFERES (2010)

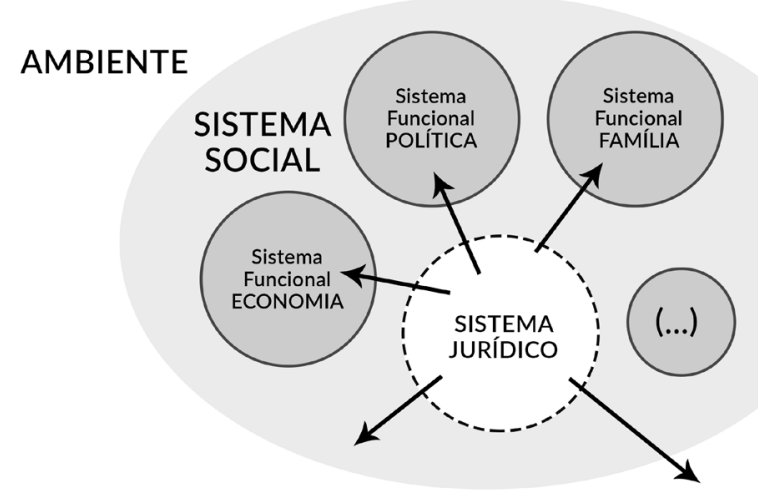

desenho esquemático representativo do fechamento operacional do sistema jurídico (dentro do sistem social) frente ao efeito autopoiético - produção de normas - e sua interação com os demais sistemas e ambiente

Fonte: ALFERES (2010)

Para Luhmann (2009), a comunicação é a única operação genuinamente social e é o principal foco do sistema social. $\mathrm{O}$ autor defende que a comunicação é a forma de interação entre o sistema e o meio e ente responsável pela estruturação interna com relação aos subsistemas. Assim, ao lançar mão de ameaças de sanção, o poder é exercido por meio da comunicação. Nesse 
sentido, segundo Luhmann (apud KUNZLER, 2004; p. 132), a falta de compreensão, a impossibilidade de chegada da mensagem ao interlocutor e a não aceitação da comunicação são três os impedimentos para uma comunicação bem sucedida.

Importa evidenciar que cada sistema tem seu próprio regramento para tornar as pessoas participantes da comunicação social. Daí a importância dos mecanismos de comunicação e acoplamento entre os diferentes sistemas sociais. Segundo Alferes (2010), por acoplamento estrutural entende-se as interações mútuas entre sistemas e com condutas comunicativas. Ao dissertar sobre o acoplamento do sistema jurídico com outros sistemas sociais, Guerra Filho afirma que

quando, por exemplo, a conduta que gerou a reação do sistema jurídico ao produzir uma norma reguladora do sistema social, é proveniente de outro sistema, fala-se na necessidade de realizar o acoplamento estrutural do sistema jurídico com outros sistemas sociais, como o político, econômico, etc. Nesse contexto a constituição é a grande responsável pelo acoplamento estrutural entre os sistemas jurídico e político (GUERRA FILHO; 2010; p. 220)

Assim, é por intermédio do acoplamento que se dá a imbricação entre as temáticas do direito e da educação, dando origem ao direito à educação. Mas a existência de tal direito, por si só, não garante aos indivíduos o ingresso nas escolas e universidades.

Desse contexto, depreende-se a importância das organizações na contemporaneidade. Segundo Magalhães e Santos Lima (2012), os acoplamentos estruturais comumente se dão por meio de organizações comuns aos sistemas envolvidos. O conceito de organização é lecionado por Maximiano como "[...] uma combinação de esforços individuais que tem por finalidade realizar propósitos coletivos. Por meio de uma organização torna-se possível perseguir e alcançar objetivos que seriam inatingíveis para uma pessoa". Face ao exposto, 
sabe-se que as organizações são dotadas de regras de pertencimento que se dão mediante seleção de pessoa e definição de papéis internos. Nas organizações as comunicações tomam a forma de decisões.

Acerca do papel das práticas de policy advocacy e sua relação com a mídia, sabe-se que os veículos de comunicação exercem um papel muito significativo quanto à influência na cultura, na formação de julgamento e atitude dos indivíduos. Howlett (2000) destaca a natureza dialética existente na relação opinião versus política, dado que a opinião pública influencia a formação de agenda formal do mesmo modo que o contrário também é verdadeiro. Daí a importância da agenda da mídia, a qual apresenta os problemas e temas considerados relevantes por parte dos meios de comunicação de modo a inseri-los na agenda pública.

Nesse contexto, importa evidenciar que Bourdieu (1997) destaca que o grau de autonomia e imparcialidade dos veículos de comunicação é proporcional a dependência econômica dos subsídios financeiros e publicidade do Estado, bem como o grau de concentração dos anunciantes. Assim, segundo Campos (2009), a opinião pública sobre as políticas pode ser influenciada pelas mídias de massa, dada a ampla acessibilidade das informações veiculadas e a possibilidade de formação de julgamento de valor realizada pelas pessoas em relação a determinados assuntos propagados pela imprensa. Gordon e Henry (2004) afirmam que as teorias atuais sobre definição de agenda de mídia indicam uma cocriação dos temas a partir das relações entre a imprensa, o público e as elites. Os autores também defendem que o sentimento coletivo de preocupação com a comunidade pode decorrer de estratégias de sensibilização e mobilização da opinião pública por parte da mídia em relação a determinado tema. Ainda nessa seara, Alferes (2010, p. 01) corrobora afirmando que "[...] o sistema político vai selecionar 
somente as informações que sirvam para manter o governo no poder, ou seja, que sirvam para que o ambiente continue obedecendo às decisões políticas".

\section{APRESENTAÇÃO E ANÁLISE DOS RESULTADOS}

Ao analisar os conceitos de policy advocacy no âmbito do campo de estudos de Políticas Públicas, Administração, Sociologia e Direitos Humanos ficou evidente que o termo policy advocacy é entendido por muitos autores como correspondente à expressão advocacy (BRELÀZ, 2007; LIBARDONI, 2000; ROLAND, 1999). Na obra intitulada "Formação de Agenda: método de policy advocacy para o ensino de políticas públicas", Secchi (2012, p. 33) define as atividades de policy advocacy como "[...] engajamento na influência da opinião pública e das agendas da mídia, política e governamental sobre a relevância de algum problema público ou proposta de intervenção [...]" e concebe o termo policy advocacy como uma espécie de sinônimo da expressão advocacy (LIBARDONI, 2000).

Dado que a função de advocacy implica em dar voz a uma mensagem ligada à defesa de uma causa, percebe-se que o conceito postulado por Secchi (2012) não defende quaisquer matizes ideológicos que a atividade de policy advocacy possa assumir como instrumento de influência da opinião pública e dos tomadores de decisão. $\mathrm{O}$ autor também não adentra nos vieses e juízos de valor que permeiam as subjetividades de análises dos campos da Filosofia, Economia e Sociologia quando das implicações associadas à classe socioeconômica dos emissores e receptores das mensagens de comunicação de policy advocacy.

Complementarmente, na obra "Coalizões em educação no Brasil: relação com o governo e influência sobre o Plano de Desenvolvimento da Educação (PDE)", de autoria de Lara Elena Ramos Simielli (2013, p. 572), a autora aborda a temá- 
tica de Advocacy Coalition Framework (ACF), ou coalizões advocatórias, que são conceituadas como

[...] atores públicos e privados, provenientes de diversas instituições e níveis governamentais, que dividem um conjunto de crenças e valores comuns e que buscam manipular as regras, orçamentos e recursos humanos governamentais visando a atingir seus objetivos no longo prazo. (SABATIER; JENKINS-SMITH, 1993, p. 25; SIMIELLI, 2013).

Nessa perspectiva, Dias (apud SOUZA, SECCHI; 2014 p. 943) define Advocacy Coalition Framework, ou coalizões de defesa como "[...] grupos de atores que se organizam, formal ou informalmente, com o objetivo de exercer pressão sobre uma determinada política pública, e assim, influenciar seu resultado [...]"

Há de se destacar que a obra intitulada "A Política Científica e Tecnológica de Santa Catarina: análise a partir do modelo de coalizões de defesa", publicada por Souza e Secchi (2014, p. 942), a terminologia advocacy vem acompanhada da expressão Advocacy Coalition Framework $(A C F)$, a qual é entendida pelos autores como um modelo que “ [...] busca compreender o processo político baseado no contexto da política [...] enfatiza aspectos como o aprendizado e o comportamento das coalizões envolvidas, bem como as alterações na política, em longos períodos de tempo [...]". Esta perspectiva vai ao encontro do pensamento de Capelari, Araújo e Calmon (2015), na obra "Advocacy Coalition Framework: Um Balanço Das Pesquisas Nacionais", quando os autores afirmam que o "[...] Advocacy Coalition Framework - ACF, ou Modelo de Coalizões de Advocacia, tem a finalidade de compreender a formulação e os padrões de mudanças nas políticas públicas [...]"

Por fim, cabe elucidar que Lane e Carter (2012) também se dedicam a descrever um dos conceitos da expressão advocacy ligado à mídia, na sua obra intitulada The Role of Evidence-based Media Advocacy in the Promotion of Tobacco Control Policies. 
Os autores abordam o termo advocacy na perspectiva de media advocacy, que se conceitua como "[...] o processo de divulgação de informações através dos meios de comunicação (gratuitos ou pagos), em que o objetivo é efetuar a ação, uma mudança de política, ou para alterar a visão do público de um problema [...]"

Ante o exposto, em termos conceituais, pode-se afirmar que para o contexto brasileiro, o termo policy advocacy implica em um conjunto de atividades estrategicamente coordenadas que objetivam defender os interesses de uma causa e promover mudanças de opiniões e conceitos por intermédio do engajamento de atores públicos dos e privados em prol de um objetivo em comum.

Face à revisão da literatura sobre os conceitos de policy advocacy, percebe-se que existe uma lacuna relativa ao estudo desta temática no cenário nacional. Trata-se de um tema ainda muito incipiente dado que são escassas as pesquisas científicas e publicações acerca desta temática no Brasil. A falta de reconhecimento do termo e de tradução da expressão para o idioma português impõe esta questão. A maioria dos estudos concernentes a temática de advocacy apresentam ênfase na análise de modelos de análise (Advocacy Coalition Framework-ACF) e na caracterização dos processos de negociação das políticas setoriais específicas, como o estudo de casos de Media Advocacy.

\section{CONCLUSÃO}

A vida em sociedade compreende uma interação contínua de um conjunto de indivíduos que possuem distintos interesses e diferentes níveis de acesso a recursos econômicos e instrumentos de poder. O termo policy advocacy implica em um apoio ativo de uma causa ou ideia, de maneira a ser expresso por intermédio de estratégias e métodos que influenciam opiniões dos tomadores de decisão. Para maximizar seus esforços, as atividades de policy advocacy demandam alianças com 
parceiros a fim de obter mais eficácia, eficiência e efetividade das ações que facilitam a combinação de competências e recursos. A composição das coalizões pode ser multi-stakeholder ou pode ainda representar os pontos de vista de um único grupo de membros, ou ainda de um único indivíduo interessado.

As campanhas de policy advocacy podem ser dirigidas ao Executivo, Legislativo ou Judiciário e podem combinar estratégias de educação pública, mobilização social e influência de parlamentares em consonância com as demandas voltadas para a inserção da causa na agenda formal, agenda pública e agenda de mídia.

A partir de uma revisão sistemática da literatura constatouse que no Brasil, ainda são recentes as pesquisas sobre policy advocacy, e a princípio, a maioria dos estudos concernentes a esta temática de advocacy apresentam ênfase na análise de modelos de análise e na caracterização dos processos de negociação das políticas setoriais específicas, estando o termo advocacy fortemente associado às temáticas de Advocacy Coalition Framework (ACF) e Media Advocacy. Ante o exposto, em termos conceituais, pode-se afirmar que para o contexto brasileiro, o termo policy advocacy implica em um conjunto de atividades estrategicamente coordenadas que objetivam defender os interesses de uma causa e promover mudanças de opiniões e conceitos por intermédio do engajamento de atores públicos dos e privados em prol de um objetivo em comum.

\section{REFERÊNCIAS}

ALFERES, E. H. Autopoiése do Direito. In: Âmbito Jurídico, Rio Grande, XIII, n. 76, maio 2010. Disponível em: <http://www.ambito-juridico.com.br/site/index.php?n link=revista_artigos_leitura\&artigo_id=7780>. Acesso em: 10 set. 2016.

ARISTÓTELES. Politica. São Paulo: Editora Saraiva, 2011.

BARDIN, L. Análise de conteúdo. Lisboa: Edições 70, 1979.

BENTHAM, J. Uma introdução aos princípios da moral e da legislação. In: BHEN- 
THAM, J. Coleção os pensadores. São Paulo, Abril Cultural, 1979.

BOBBIO, N.; MATTEUCCI, N.; PASQUINO, G.; Dicionário de política. Brasília, Universidade de Brasília, 1998.

BOURDIEU, P. Sobre a televisão. Rio de Janeiro: Ed. Jorge Zahar, 1997.

BRELÁZ, G. Advocacy das Organizações da Sociedade Civil: principais descobertas de um estudo comparativo entre Brasil e Estados Unidos. XXXI Encontro ANPAD, 2007. Disponível em: <http://www.anpad.org.br/admin/pdf/APS-A1916.pdf >. Acesso em: 12 jan. 2015.

BRUM, J. F. Advocacy journalism: uma análise de Le Monde Diplomatique Brasil. Trabalho de Conclusão de Curso (Monografia). Curso de Comunicação Social (Habilitação em Jornalismo). Faculdade de Comunicação Social (Famecos). Pontifícia Universidade Católica do Rio Grande do Sul (PUCRS). Porto Alegre, 2009.

CALMON, P. C. P.; COSTA, M. análise de políticas públicas no brasil: estudos sobre a formação da agenda governamental. XXXI Encontro da Associação Nacional de PósGraduação em Administração. Rio de Janeiro, 2007. Disponível em: <http://www. anpad.org.br/admin/pdf/APS-B890.pdf > . Acesso em: 12 fev. 2015.

CAMPOS, M. S. Mídia e Política: a construção da agenda nas propostas de redução da maioridade penal na Câmara dos Deputados. Opinião Pública, Campinas, vol. 15, n 2 , Novembro, 2009, p.478-509

CAPELARI, M. G.M; ARAÚJO, S. M. V. G.; CALMON, P. C. P. Advocacy coalition framework: um balanço das pesquisas nacionais. Administração Pública e Gestão Social, 7(2), abri.-jun. 2015, 91-99.

COMPARATO, F. K. A afirmação histórica dos direitos humanos. 4. ed. ver. e atual. São Paulo: Saraiva, 2006.

CRESWELL, J. W. Projeto de pesquisa: métodos qualitativo, quantitativo e misto. 3.ed. Porto Alegre: Artmed, 2010.

CRÜSEMANN, Frank. A Torá: teologia e história social da lei do antigo testamento. São Paulo: Editora Vozes, 2001.

DALLARI, S. G. et al . Advocacia em saúde no Brasil contemporâneo. Rev. Saúde Pública, São Paulo, v. 30, n. 6, Dec.1996 .Disponível em: <http://www.scielo.br/scielo. php?script $=$ sci arttext\&pid=S0034-89101996000600014\&lng=en\&nrm=iso $>$. Acesso em: 28 jan. 2015 .

DIAS, R. B. A trajetória da politica científica e tecnológica brasileira: um olhar a partir da análise de política. Tese (doutorado) - Instituto de Geociências, Universidade de Campinas, Campinas, 2009.

DEMO, P. Metodologia do conhecimento científico. São Paulo: Atlas, 2000.

EASTON, D. A framework for polititical analysis. Englewood Cliffs, N. J.: Prentice-Hall, 1965. Disponível em: < http://journals.cambridge.org/action/displayAbstract?fromPa$\mathrm{ge}=$ online\&aid $=8746706 \&$ fileId $=$ S000305540008045X $>$. Acesso em: 20 abr. 2015.

FERENHOF, H. A.; FERNANDES, R. F. Passos para a construção da revisão sistemática e bibliometria. Disponível em: $<$ http://www.igci.com.br/artigos/passos_rsb.pdf > Acesso em: 21 abr. 2015. 
FOX, J. Vertically Integrated Policy Monitoring: A Tool for Civil Society Policy Advocacy. Nonprofit and Voluntary Sector Quarterly, vol. 30, no. 3, September 2001. Disponível em: < http://nvs.sagepub.com/content/30/3/616.full.pdf > . Acesso em: 21 abr. 2015.

HASHIZUME, C. M. Política e instituições: possíveis articulações teóricas. Revista Reflexão e Ação, Santa Cruz do Sul, v.22, n.2, p.424-441, jul./dez.2014. Disponível em: < https://online.unisc.br/seer/index.php/reflex/article/view/2224/3700 > . Acesso em: 16 jan. 2015.

HOWLETT, M. A dialética da opinião pública: efeitos recíprocos da política públicae da opinião pública em sociedades democráticas contemporâneas. Opinião Pública, Campinas, v.6, $\mathrm{n}^{\mathrm{o}} 2,2000$.

KUNZLER, C. M. A Teoria dos sistemas de Niklas Luhmann. Revista Estudos de Sociologia, Araraquara, 16, 123-136, 2004.

LIBARDONI, M. Fundamentos teóricos e visão estratégica da advocacy. Revista de Estudos Feministas. V. 8. N. 2. ISSN 0104-026X, Florianópolis, Brasil, 2000. Disponível em: < https://periodicos.ufsc.br/index.php/ref/article/view/11936/11202>. Acesso em: 12 jan. 2015.

LUHMANN, N. O conceito de sociedade. In: NEVES, C. B. ; SAMIOS, E. M. B. (Org.). Niklas Luhmann: a nova teoria dos sistemas. Porto Alegre: Ed. UFRGS, 1997.

LUHMANN, N. La sociedad de la sociedad. México: Herder, 2007.

LUHMANN, Niklas. Introdução à teoria dos sistemas. Petrópolis: Vozes, 2009.

MAGALHAES, J. N. ; SANTOS LIMA, E. Direitos humanos e políticas públicas: as duas faces de Janus. Anais do [Recurso eletrônico] XXI Encontro Nacional do CONPEDI. 1ed.Florianópolis: Fundação Boiteux, 2012, p. 10076-10095.

MASCARENHAS, A. O.; ZAMBALDI, F.; MORAES, E. A. rigor, relevância e desafios da academia em administração: tensões entre pesquisa e formação profissional. São Paulo, RAE-Revista de Administração de Empresas, v. 51, n. 3, maio/jun. 2011, p. 265-279.

MAXIMIANO, A. C. A. Introdução a administração. 3. ed., São Paulo, Editora Atlas, 1992.

MORAES, R. Análise de conteúdo. Revista Educação, Porto Alegre, v. 22, n. 37, p. 7-32, 1999.

NAVARRO, P.; DÍAZ, C. Análisis de contenido. In Métodos y técnicas de investigación en ciencias sociales. Editores: Juan Manuel Delgado y Juan Gutiérrez. Editorial Síntesis. Madrid. 1994.

NICOLAI, A; SEIDL, D. That's relevant! Different forms of practical relevance in management science. Organization Studies, v. 31, n. 9\&10, p. 1257-1285, 2010

OLIVEIRA, A. C. J. Lobby e representação de interesses: lobista e seu impacto sobre a representação de interesses no Brasil. 2004. Tese (Doutorado). Instituto de Filosofia e Ciências Humanas da Universidade de Campinas Unicamp. São Paulo, 2004. Disponível em < http://www.bibliotecadigital.unicamp.br/document/?code=vtls000316902\&opt=4 >. Acesso em: 28 jan. 2015. 
PORTO, L. M. F. Lobby: Conceituação e análise das propostas legislativas de regulamentação da atividade no Brasil à luz da lei do lobby estadunidense. Monografia do Curso de Direito da Faculdade de Ciências Jurídicas e Sociais no Centro Universitário de Brasília (UNICEUB). Brasília, 2011. Disponível em: < http://repositorio.uniceub. br/bitstream/123456789/312/3/20660929.pdf >. Acesso em: 27 jan. 2015.

ROLAND, E. M. S. Feminismo: Ações políticas e instâncias de poder. Revista Estudos Feministas, Florianópolis, v. 8, n.2, 2000. Disponível em: <https://periodicos.ufsc.br/ index.php/ref/article/view/11938/11204 >. Acesso em: 27 jan. 2015.

RODRIGUES, A. Advocacy: uma ação política de novo tipo. Centro Feminista de Apoio e Acessoria. 1999. Disponível em: <http://www.cfemea.org.br/publicacoes/artigos_detalhes.asp?IDArtigo $=6>$. Acesso em: 28 abr. 2015.

RUA, M. G. Politicas públicas. Florianópolis: Departamento de Ciências da Administração / UFSC; [Brasília]: CAPES: UAB, 2009. Disponível em: <http://portal.virtual. ufpb.br/biblioteca-virtual/files/pub_1291087408.pdf>. Acesso em: 21 dez. 2013.

SABATIER, P.; JENKINS-SMITH, H. Policy change and learning: an advocacy coalition approach. Colorado: Westview Press, 1993.

SANTOS, M. Por uma outra globalização: do pensamento único à consciência universal. 14. ed. Rio de Janeiro, Record, 2007.

SECCHI, L. Formação da Agenda: método de Policy Advocacy para ensino de Políticas Públicas. Revista de Administração Pública e Gestão Social. APGS, Viçosa, v. 4. n.1, pp. 32-47, abr./jul. 2009. Disponível em: <http:/www.apgs.ufv.br/index.php/apgs/ article/view/55\#.VLPvxdLF8ut>. Acesso em: 12 jan. 2015.

. Política públicas: conceitos esquemas de análise, casos práticos. 2. ed. São Paulo: Cengage Learning, 2013.

SCHERER-WARREN, I. Movimentos sociais e participação. In: SORRENTINO, Marcos (Coordenador). Ambientalismo e participação na contemporaneidade. São Paulo: EDUC/FAPESP, 2001.

SIMIELLI, L. E. R. Coalizões em educação no Brasil: relação com o governo e influência sobre o Plano de Desenvolvimento da Educação (PDE). Rev. Adm. Pública - Rio de Janeiro 47(3):567-586, maio/jun. 2013

SOUZA, L. R.; SECCHI, L. A política científica e tecnológica de Santa Catarina: análise a partir do modelo de coalizões de defesa. Rev. Adm. Pública - Rio de Janeiro 48(4):939-960, jul./ago. 2014.

VIARO, M. E. A importância do latim na atualidade. Revista de Ciências Humanas e Sociais, São Paulo, Unisa, v. 1, n. 1, p. 7-12, 1999.

TOCQUEVILLE, A. A democracia na América. 4. ed. Belo Horizonte: Itatiaia, 1998.

Artigo recebido em: 31/05/2017

Artigo aprovado em: 05/10/2017 